Página inicial: 147 - Página final: 164

Tipo de artículo: de investigación

\title{
Violencia urbana y estrategias de protección de mujeres en Cali (Colombia) ${ }^{3}$.
}

Urban violence and protection strategies of women in Cali (Colombia).

Recibido: julio de 2015 Revisado: octubre de 2015 Aceptado: noviembre 20 de 2015

Por: Alejandra Sánchez Zapata ${ }^{1}$ y Silvia Cristina Caicedo Muñoz ${ }^{2}$.

\section{Resumen.}

Esta investigación reconstruye las estrategias de protección en contextos urbanos desde fragmentos de la historia de vida de dos mujeres víctimas de la violencia social y política, para ello se usó la metodologia feminista en psicologia comunitaria, la cual reconoce en el discurso femenino, la experiencia de vida como fuente de saberes legitimos. (Campbell \& Wasco, 2000). Los resultados evidencian que las mujeres utilizan estrategias de protección basadas en los saberes construidos en su experiencia de vida, su sitio de origen y las relaciones de poder. Pone de manifiesto la relevancia de investigar sobre la violencia urbana.

\section{Palabras claves.}

Violencia urbana, estrategias de protección, investigación feminista, psicología comunitaria.

\section{Abstract.}

This piece of research reconstructs the protection strategies in urban contexts from fragments of life histories from two women, victims of the social and political violence. For such a purpose, a feminist methodology in community psychology was used, which recognizes, in the feminist discourse, the life experience as a source of legitimate knowledge (Campbell \& Wasco, 2000). The results make evident that women use protection strategies based on the knowledge built in their life experience, their place of origin, and the power relationships. It reveals the relevance of researching on urban violence.

\section{Key words.}

Urban violence; Protection strategies; Feminist research; and Community psychology.

\footnotetext{
${ }^{1}$ Psicologa investigadora, Universidad San Buenaventura de Cali. Colombia. Contacto: alejasaza@hotmail.com.

${ }^{2}$ Candidata a Doctora en Administración en la línea de Gobierno y Politicas Públicas, Universidad del Valle, Cali-Colombia. Magíster en Políticas Públicas, Universidad del Valle, Cali-Colombia. Psicóloga, Universidad de San Buenaventura, Cali-Colombia. Profesora hora cátedra del programa de Psicología, Universidad de San Buenaventura-Cali. Con intereses Investigativos en estudios feministas en psicología comunitaria, empoderamiento y estudios organizacionales. Contacto: silvia.cristina.caicedo@gmail.com - sccaiced@usbcali.edu.co
} 


\section{Introducción.}

La violencia urbana, se deriva del conflicto armado en Colombia. Este se constituye como "una constante en nuestra historia. Esto se debe a la dispersión geográfica y a la debilidad del Estado, sumada a la incompetencia y la manipulación del poder por parte de los gobernantes". (Leal Buitrago, 2012). Ha causado efectos devastadores sobre las personas y las comunidades, obstaculizando el desarrollo del país, ya que el número de secuestros, homicidios y desplazados aumentan en los Municipios donde los grupos ilegales o grupos armados tienen presencia significativa. (Sánchez Torres \& Diaz, 2005).

Uno de los efectos relevantes sobre los tipos de violencia que viven las mujeres en el marco del conflicto armado, los cuales son nombrados por la Organización femenina popular y que resaltan en un observatorio de las violencias y la discriminación contra las mujeres en el Magdalena medio. Se habla en dicho observatorio que las mujeres se convierten en víctimas de violencia sexual, pero no solo están expuestas a este tipo de violencia, sino que también son blanco para torturas, víctimas de delitos contra la libertad y amenazas contra las mimas (Organización femenina popular, 2014)

$\mathrm{Al}$ respecto el texto "la verdad de las mujeres víctimas del conflicto armado en Colombia" realizado por la Ruta Pacifica de las Mujeres, tuvo como objetivo visibilizar las voces en el ejercicio de la construcción de la verdad colectiva narrada por ellas y que forma parte de la historia reciente de Colombia. De este informe se considera relevante tópicos como: Mujeres víctimas y sobrevivientes del conflicto armado Colombiano, Afrontamiento y resistencia de las mujeres- De la protección a la reconstrucción de sus vidas y la transformación de su rol, los hechos de violencia, asesinatos, ejecuciones extrajudiciales, masacres y desapariciones forzada, las amenazas, la dimensión colectiva de la violencia contra las mujeres, las demandas de las mujeres, de la irreparabilidad a la reconstrucción.

El primer aparatado del informe realizado por la Ruta Pacífica de las Mujeres, evidencia como constante en los relatos sentimientos de inseguridad, duda, contradicciones acerca de la identidad o el reconocimiento de quienes perpetraron la violencia en sus lugares de origen, esto como respuesta al miedo frente a lo que han tenido que vivir por parte de los actores que las han violentado.

A partir de lo anterior se indaga acerca de si esto es lo que utilizan ellas como un mecanismo de protección, a lo que se responde que hay una gran posibilidad de que así sea, puesto el conflicto aún está vigente, y ellas todavía no se sienten lo suficientemente seguras para expresar todo lo acontecido por miedo a ser re-victimizadas. (Ruta pacífica de las mujeres, 2013)

Es así como esta investigación cobra relevancia, en tanto se evidencia que el conflicto está vigente, y es aquí cuando se debe decir, que no solo es conflicto que causan los grupos armados al margen de la ley, sino también el conflicto que se encuentra en los contextos urbanos; a los que están expuestas las mujeres que han sido desplazadas en algún momento de sus respectivos lugares de origen.

Referir la violencia urbana o violencia en contexto urbanos, implica centrarse en la Ciudad. Entre los años 70, 80 y principios de los 90, Cali aumentó su oferta laboral, en los sectores 
de la construcción, el comercio y la diversión nocturna. Lo que generó movilización de personas a la ciudad con el ánimo de encontrar diferentes oportunidades de empleo y así mejorar sus condiciones de vida. (Oficina Gestión de paz y convivencia de la Gobernación del Valle, 2005).

En consecuencia incrementó la población de los sectores oriental y ladera, provenientes del Pacifico Colombiano, pueblos indígenas de los departamentos del Cauca, Nariño y un gran porcentaje de población Antioqueña que se establecieron en la parte comercial formal e informal (Oficina Gestión de paz y convivencia de la Gobernación del Valle, 2005).

La Ciudad de Santiago de Cali se viene considerando como un Municipio receptor en el tema de desplazamiento, situación similar a la que viven las demás ciudades capitales del país (Oficina Gestión de paz y convivencia de la gobernación del Valle, 2005). Según el Diagnostico socio- demográfico de la población en situación de desplazamiento (PSD) en Cali dice:

"En esta ciudad, según las cifras del SUR -Sistema Único de Registro- de la Red de Solidaridad Social se encuentran en situación de desplazamiento 30.288 personas 14, que representan 7.152 familias (el CODHES en su boletin No. 56 indica que a Cali llegaron en las 2.004, 6.570 personas desplazadas).

Estos acumulados se vienen sistematizando desde 1.999; sin embargo, la Comisión de Vida Justicia y Paz de la Arquidiócesis de Cali, realizó en 1997, un registro sistemático de información, en donde presentaban las siguientes cifras:

- Entre 1990 y 1996, habrían llegado a Cali 45.000 personas desplazadas que representaban 9.000 hogares.

- De éstas la mayoría eran mujeres y menores de edad.

- En promedio, según el informe, llegaban a Cali 3 familias desplazadas por día provenientes de diferentes regiones del pais" (Oficina Gestión de paz y convivencia de la gobernación del Valle, 2005).

En el año 2001 Cali tuvo una fuerte oleada de familias desplazadas. Para ese momento la Personería de Cali, en un informe rendido al Comité Municipal de Atención a Población Desplazada en el mes de septiembre de ese mismo año, afirmaba que estaban llegando aproximadamente treinta y cuarenta familias diariamente a declarar como desplazadas (Oficina Gestión de paz y convivencia de la gobernación del Valle, 2005).

Con la problemática de desplazamiento de base, se hace importante darle voz a las mujeres que llegan a estos nuevos contextos urbanos, donde se ven inmersas en mundo diferente, tanto ellas como sus familia y llegan nuevamente a ser victimizadas, pero ya no por una violencia socio-política, sino por una violencia urbana, es decir aquella que se produce en el contexto que las recibe, barrio, albergue, asentamiento u otro, que las hace proclive a situaciones de vulneración y violencia. Ello se ofrece como problemática para investigar, para éste caso se pretende dar voz a mujeres desplazadas, para vislumbrar de qué forma ellas hacen uso de estrategias para enfrentar la violencia urbana en la ciudad de Cali. 
Esta es una investigación en psicología comunitaria, con enfoque feminista que se realizó con dos mujeres desplazadas de Satinga- Nariño que actualmente residen en Cali, específicamente en la zona del Distrito de Agua Blanca y están expuestas a contextos de violencia urbana. Se identificaron las estrategias de protección que utilizan estas mujeres ante este tipo de violencia que se da en el contexto en el que viven.

\section{Metodología.}

Se utilizó la metodología feminista en psicología social comunitaria ( Campbell \& Wasco, 2000). Esta metodología feminista reconoce que las mujeres han vivido diferentes experiencias como fuentes legitimas de conocimiento, de esta manera esta metodología trata de erradicar los prejuicios sexistas en las investigaciones y atrapar las voces de las mujeres que son coherentes con ideales feministas. (Campbell \& Wasco, 2000, pág. 773). Esta investigación se caracteriza por ser reflexiva, se centra en la mujer y en la deconstrucción de sus experiencias, la transformación de la sociedad y el empoderamiento, los cuales se definen desde (Fonow \& Cook, 1991, p. 2) (Campbell \& Wasco, 2000),

- La ampliación de metodologías para incluir métodos cuantitativos y cualitativos que conecta las mujeres para la recolección de datos a nivel de grupo

- La reducción de la relación jerárquica entre los investigadores y sus participantes que facilita la confianza y la divulgación

- El reconocimiento y la reflexión sobre la emotividad de vida de las mujeres (Cam001pág. 773)

Para las autoras, existen diferentes tipos de metodologias. En este caso utilizaremos la metodología posmodernista, la cual se resiste a que existe una sola noción de la verdad o realidad, planteando el concepto de verdad como una "ilusión destructiva". (Campbell \& Wasco, 2000, pág. 782, at a Olesen, 1994, p. 164)

En consecuencia, se buscaron dos (2) mujeres que vivieran en barrios construidos para reubicación a población en situación de desplazamiento y con situaciones de violencia social-urbana. Las mujeres participaron en la investigación de manera voluntaria, pero fueron seleccionadas de acuerdo a los siguientes criterios: a) Origen: Costa Nariñense Colombiana; Género: Mujer; Edad: Adulta joven (20-40 años); etnia: Afrodescendiente y Tiempo de residencia en Cali: no menos de 3 años a la fecha de inicio de esta investigación Con el fin de conocer de manera fidedigna sus relatos, se hicieron entrevistas a profundidad y se complementó la información con Cartografia social. Cada entrevistada diligenció el consentimiento informado.

Las técnicas usadas fueron los fragmentos de historia de vida en el periodo 2010-2013, para lo que se aplicaron entrevistas a profundidad en torno: a) Cómo era su vida en el sitio de origen; b) Situaciones y motivos de desplazamiento; c). Para las Historias de vida, se definió

También se usó la cartografia social, en la cual las mujeres plasmaron en un mapa los lugares donde viven, los más significativos (que representan miedo, temor o seguridad) a sus alrededor, como se muestra a continuación: 
Ilustración 1 Cartografía de la zona de vivienda actual de la Mujer E

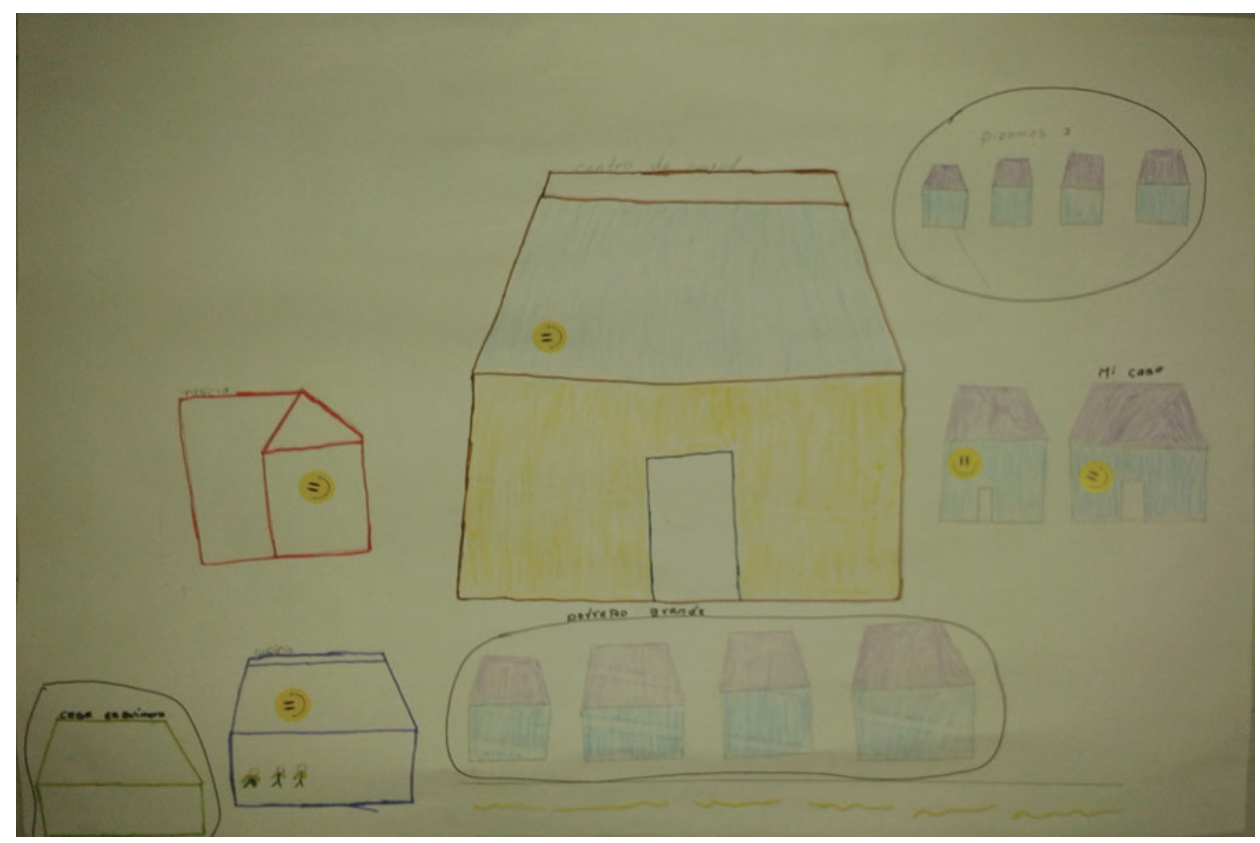

La participante expresó que los lugares que le generaban confianza y seguridad, eran las casas que quedaban cerca a la suya, debido a que conocía a las personas que viven en cada una de ellas; mientras le generaban inseguridad, aquellas que se encontraban a más de una cuadra su vivienda, debido a que no conocía a sus residentes y sus comportamientos. Expresa "pues por más cerca que queden de mi casa, porque una cuadra no es tan lejos, a mí me dan miedo, porque uno no conoce quien vive alli y pues eso es inseguro".

Ilustración 2 Cartografia de la zona de vivienda actual de la Mujer N

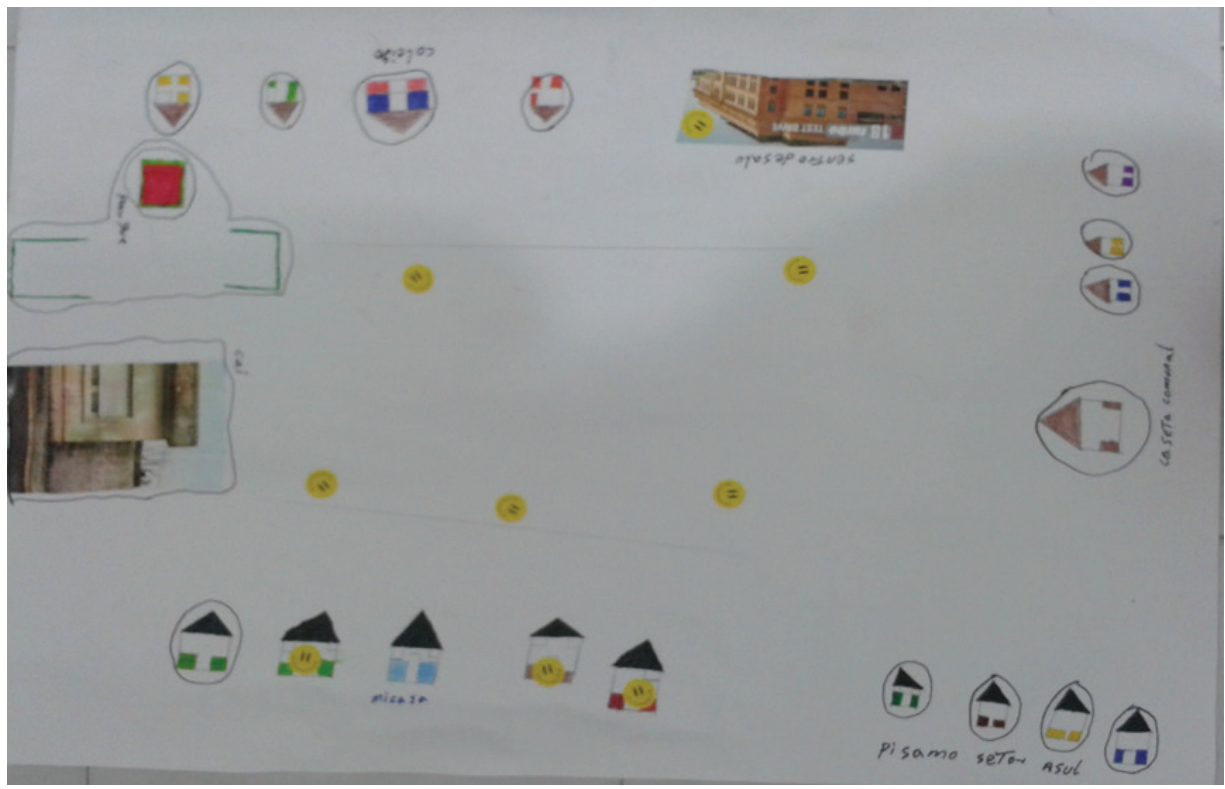


La entrevistada expresó que los lugares que para ella generaban seguridad, eran las casas colindantes a la suya, pues evita relacionarse con otros para proteger a sus hijos de juntas "que no son buenas". De la misma forma, manifiesta que los lugares inseguros para ella, son instituciones como el CAI de la policía debido a que para ella, estos no hacen nada para proteger a los habitantes de ese barrio. Agrega "vea es que ellos son los policías y deberian protegerlo a uno, pero a ellos le matan la gente al lado y ellos solo salen a recoger al muerto, entonces para mi ellos son inseguros, yo paso por ese CAI y a mí me da miedo".

\section{Resultados.}

La estrategia de análisis de información se estableció a partir de las visitas realizadas a las mujeres y de la información recopilada en las entrevistas a profundidad; a partir de tres niveles:

- Nivel de análisis I- Describir las prácticas de las mujeres, en la resolución de situaciones de violencia/conflictos al interior de su comunidad.

- Nivel de análisis II -Caracterizar las creencias que las mujeres expresan en las estrategias utilizadas para la resolución de situaciones de violencia/conflictos.

- Nivel de análisis III- Identificar los valores de las mujeres inculcados al interior de su comunidad, a partir de su cultura.

Esto permitió clasificar la información considerando diferencias y semejanzas de mecanismos de protección usados por las mujeres en situaciones de conflicto urbano.

En un segundo momento de tratamiento de los datos, los mecanismos de protección identificados se caracterizaron según creencias, prácticas y valores presentes en los discursos de las mujeres.

Por último, los hallazgos producto de la clasificación de los relatos fueron analizados con relación a elementos de los siguientes tópicos del informe de la comisión de la verdad de las mujeres víctimas del conflicto armado en Colombia: Mujeres víctimas y sobrevivientes del conflicto armado Colombiano, Afrontamiento y resistencia de las mujeres- De la protección a la reconstrucción de sus vidas y la transformación de su rol, los hechos de violencia, asesinatos, ejecuciones extrajudiciales, masacres y desapariciones forzada, las amenazas, la dimensión colectiva de la violencia contra las mujeres, las demandas de las mujeres. De la irreparabilidad a la reconstrucción.

A continuación se presentan los discursos de las dos mujeres clasificados según categorias que emergieron de los mismos relatos.

\section{La reconstrucción histórica en fragmentos de historia de vida.}

¿De dónde vienen?

Las mujeres de 38 años y 33 años, son oriundas de zonas rurales del litoral pacífico. Sus relatos manifiestan la distancia entre su sitio actual y el lugar donde dejaron sus raíces: 
Yo vengo de Satinga, eso queda en Nariño, de una vereda que se llama Cepangué. Yo vivía con mi esposo y los tres, mis dos hijos y yo (E, 2014).

Tengo 4, dos mujeres y dos hombres (...) pero de una vereda que le dicen "Cepangué" (N, 2014).

Asimismo los relatos resaltan las prácticas sociales y culturales en el municipio donde habitaban:

Yo vivía con mi esposo y mis 4 hijos, pero tenía familia, por ahí, pues estaban mis papás, la familia de mi esposo y los amigos que como uno los conocía hace rato (...) Pues siempre eran lejitos las casas. Eso, y pues los que vivian alli eran amigos de uno (...) nos conociamos todos los vecinos. Ah si y asi nos sentiamos seguros [dejaban las casas solas], pues tranquilos de que nada se iba a perder (...) allá entre todos nos colaborábamos_(...) nos reuniamos todos los de la vereda a hacer fiestas y compartiamos entre todos (E, 2014).

(...) allá las casas como son de madera, hasta habia veces que yo me olvidaba de cerrar la puerta (...) y uno se iba para las fiestas de las otras veredas y se quedaba tranquilo, porque sabia que nada le iba a pasar a las cosas de uno, cuando uno volvía encontraba todo igual. Igual, nos daba igual, sabe que era el miedo que yo tenía allá, que pues por allá uno tienen un costumbre que hay unas visiones que les dicen la tunda (risa)...es una visión del monte que se lleva a los niños dizque (risa) o sea eso es que uno le tenía miedo, pero que ya gente iba a hacer daño a un no señor (...) uno se iba a otras veredas a fiestiar que los dos días que nos invitaban a asi a otras veredas y uno la casa si quería la dejaba cerrada y si no quedaba abierta y le quedaban televisor, nevera, nadie le tocaba nada a nadie. Todos éramos como una familia grande, pues no ve que uno veía a los niñitos de los vecinos desde bebecitos asi andando pa'arriba y pa'abajo con los hijos de uno, entonces uno estaba tranquilo porque ya a todos los conocía y eso que a veces a los de las otras veredas también los conocíamos y estábamos en confianza (...) O sea que si aqui donde está usted, usted iba a trabajar allá, a usted si usted no tenía trabajo uno le buscaba (...) los trataba bien, allá llegaban jóvenes, muchachas a trabajar, a como igual como uno viene a buscar trabajo acá, también llegaban muchachas, mi papi también las recibia hasta en la casa de ellos a vivir (N, 2014).

Pues yo allá me sentía un poco mejor porque yo no vivía como antes de entrar la guerrilla a allá, yo no vivía como preocupada que ay es que mi hijo no puede bajar donde la vecina, porque se le puede caer un tiro perdido, que hay que mi hijo no puede jugar con ese niño porque ese niño mete vicio, no alla no, pues en la vereda donde nosotros vivimos allá no se ve vicio nada de eso, que un niño le va a dar a otro niño, nada de eso (N, 2014).

Allá juegan futbol los niños desde que están así como P ya andan jugando, uno no les pone cuidado a los niños cuando están jugando (N, 2014).

Eso los más grandes cuidan a los más pequeños y asi ahí donde esta P fuera mi hijo allá en el Nariño, él me decía que iba a jugar y él se iba a la cancha como de aqui a donde doña $S$ se iba solo en gallada de los más grandecitos a jugar allá y uno no estaba pendiente que podia pasar algo ( $N$, 2014). 
No más, el mar que se podían ahogar los que no sabian nadar, pero los que sabian nadar ya sabian ( $N$, 2014).

Los roles de las mujeres y la sostenibilidad emocional y económica de las familias estaba asociada al uso de recursos propios o de la comunidad para satisfacer sus necesidades de alimentación, vivienda y educación.

Vea en Satinga uno se iba a coger cangrejos, cogía camarón, vendía cocos, vendía plátanos, lo que se diera, el problema es que uno no siempre tenía la plata para irse al pueblo a venderlo entonces pues no podiamos trabajar, pero igual eso servía porque uno comía con eso y pues uno se compartía a veces con los vecinos o ellos le regalaban a uno cosas, pero pues igual no le faltaba uno nada.

Yo por lo menos no podia ir a vender cada 8 dias al pueblo porque como le dije yo tenía que buscar con que irme, pero puyes igual salia a coger mis cangrejos o lo que hubiera para hacer comida, y pues al pueblo a veces nos íbamos varias a vender y eso se vendia fácil (E, 2014).

En Satinga, mi esposo trabajaba la madera, osea pues hacian cosas con ella, la lijaban, la trabajaban en los aserrios y yo cogía cangrejo, o a veces iba a coger camarón, pescado y pues las cosas que uno tenía sembrado en su casa (N, 2014).

Situaciones y reacciones: ¿por qué se desplazan?

Ambas mujeres relatan cómo diferentes actores al margen de la ley incidieron en la decisión de salir de su lugar de vivienda.

Nosotros nos vinimos para acá porque se metieron y nos amenazaron, se metieron los guerrilleros, bueno primero los paras y uno se asustaba, pero después la guerrilla y uno vivia muy asustado y nos amenazaron y nos vinimos, pues mi esposo ya habia muerto, nos vinimos mi hijo y mi hija (E, 2014).

Noo!!! siempre pasaron cosas!!, o sea teníamos como que (silencio) como tres años de venir pasando eso, ósea primero se metieron los paras y asustaban a los niños, lo asustaban a uno, bueno en fin lo amedrantaban porque querian que uno obligatoriamente les diera hasta la comida, a ellos ( $N$, 2014).

También, señalaron las formas de intimidación ejercidas por los grupos al margen de la ley:

Pero por lo menos el camarón, cuando entró la guerrilla uno ya no lo podía coger, porque ellos echaban esos muertos al agua y esos camarones se pegaban de esa gente y pues uno no podía comerse eso, entonces ya no comíamos camarón (E, 2014).

Ujunm y dárselas a ellos, o sea ellos salían del monte por ahí y cuando la guerrilla ya se dio de cuenta que los paras se estaban quedando ahí, ya se metió la guerrilla queriendo matar la gente, ósea y si usted nunca le daba un vaso de agua a los paras a usted no le hacian nada pero si a usted los paras le habian obligado a darle un vaso de agua, asi 
fuera un vaso de jugo y ellos se daban de cuenta venian a matarlos a usted, porque según ya uno era para, no sería (...) Ujunm, pero es que cuando ellos entraron a allá nadie sabía que eran paras, ellos andaban vestidos normal, como uno ya después es que andaban ya vestidos con sus uniformes. Eran como los de la pintetriga sino que tenían otra marca aquí (señala la altura del hombro, en la manga del brazo derecho) (N, 2014).

(...) se quedaron ellos, adueñándose de todo (se rie un poco). O sea de lo que uno vivía tenía que darle a ellos, nosotros allá vendiamos madera, teníamos locales y ellos ósea si usted bajaba pal pueblo a comprar, tenía que darle como la mitad de lo que uno llevaba del mercado que uno llevaba (...) es que uno se mantenía amedrantado con miedo (N, 2014).

Según ellas sus decisiones de proteger la vida propia y de sus hijos estuvo asociada a la posibilidad de ser víctimas del reclutamiento infantil o la desaparición forzada.

A nosotros pues ellos llegaron, o sea llegó la guerrilla y nos dijo que nos teníamos que ir porque si no se llevaban a mi hijo, porque necesitaban personas, y pues decian que teniamos que hacerles caso en lo que ellos nos decian (E, 2014).

No porque la primera vez que se entró la guerrilla, se metieron al monte donde estaba un primo mio y lo mataron, lo dejaron ahí muerto y la mujer pues se escapó y ya cuando una noche estábamos todos ya acostados y se metieron y Carlos (esposo de la entrevistada) él tenía un motorcito y querían obligarlo a él que les juera a hacer viaje a esa hora (...) A uno y como él no quiso, él no quería lo amenazaron todo, ósea lo asustaron a todos nosotros que cuando volvieran, si él no quería se iba a morir (N, 2014).

Hacian (retenes en los aserrios), pero ya no, cuando nosotros estábamos ellos hacian y la persona que no tenían cédula como las jóvenes que no tenían cedulas, ellos la dejaban ahi y abusaban de ella ósea hacian que ellas les cocinara y se acostaran con ellos, podian tener marido, hijos (...) las que no querian pues si las mataban y las botaban al agua, pero las que pues aceptaban para no morirse tenian que hacer lo que ellos querian (N, 2014).

Sacamos porque a todos los jóvenes ellos querian adueñarse de los jóvenes, de los jovencitos (N, 2014).

(...) a los paras porque la guerrilla, si a ella le decían que usted era para, ella no la mataba a usted de una vez primero la investigaba pero si a los paras le decian que yo era guerrillera, ellos no me preguntaban si yo era guerrillera sino que me iban matando a mi y a mis hijos, a toda la familia o sea y si las dos viviamos en la vereda y éramos enemigas que peleáramos yo iba al grupo de los paras y le decía que usted era guerrillera y ellos a usted no le preguntaban sino que la mataban a usted y sus niños, podian estar recién nacidos, en la vereda de nosotros eso no paso pero en las otras si (N, 2014).

Ujunm, en la vereda de nosotros todos eran miedosos entonces nadie maleaba a otro podía tener un enemigo, podia tener un mal entendido pero nadie maleaba a nadie. Fíjeme a mi si él muchacho enfermó a mi papá y le pegó ese poco de machetazos y se fueron los paras él quedo ahi y cuando se metió la guerrilla él estaba ahí y yo en ningún momento tuve valor decirle mire es que ese es para, porque es que me daba miedo hacerlo matar, $y$ 
si merecía eso, pero yo no se lo hice y éramos enemigos, porque es un enemigo y yo nunca le hice esa maldad (N, 2014).

o con su uniforme, ellos si dentraron con su uniforme de una vez, y ellos se llevaron una muchacha amiga de nosotros de la misma edad de nosotros. Ella tenía un niño pero no tenía marido y una vez fue pal pueblo de Satinga y cuando iban dentrando se la sacaron de la lancha y se la llevaron y hasta hoy dia no ha aparecido (N, 2014).

Las estrategias de protección de las mujeres implicaron apoyo en redes comunitarias con personas que representan en sus comunidades de origen un lugar de legitimidad o autoridad, en tanto las relaciones de poder entre ellas y las personas les permiten solidaridad y cooperación para salvaguardar sus vidas, así como viabilidad en las maneras de salir. Es de anotar que las mujeres tienen un discurso predominantemente del "nosotros" que supone la existencia de una identidad común.

Nosotros, pues un señor vecino de nosotros que tenía un motor (lancha) nos sacó en la madrugada de allá, porque a esa hora era que los de la guerrilla no estaban, porque en el día mantenía por la vereda asustando a la gente y pues no podian ver que nosotros nos fuéramos de allá, y pues él fue muy amable y como eramos amigos nos sacó de allá, gracias a él pues salimos fácil (E, 2014).

(...) nos íbamos a venir, Carlos decía que no, que esos no volvían más y después un vecino le fue a decir que venian (...) nosotros salimos de la casa y nos pasamos a una casa de la vecina y después el marido de ella, vino y nos dejó al pueblo de Satinga, pero nosotros no sacamos nada. Nosotros alcanzamos a a sacar no más alguna ropita que la vecina nos trajo, hasta los papeles de mis hijas quedaron perdidos, después fue que yo los recuperé porque mi mamá fue para allá a la muerte de un tío y los saco los papeles y los trajo (N, 2014).

¿Por qué Cali y no otra ciudad? se convierte en una pregunta relevante luego del desplazamiento, ante ello las mujeres manifestaron que:

Pues nosotros de allá de la costa, pues primero llamé a una señora que estaba acá y le dije que nos diera posada en su casa y ahi empezó, porque pues ya la conocíamos y era más fácil llegar acá porque teníamos a donde llegar y pues paramos ahí como que como 1 año $y$ de ahi fue que nos vinimos a la invasión (E, 2014)

Porque acá estaban mi hermana, mi mamá pues ellos ya eran desplazados la primera vez porque a mi papá lo iban a matar, a mi papá le metieron 11 machetazos, entonces era más fácil que llegáramos a Cali a reunirnos con mis papás y pues mis hijas ya se habian venido $(\mathrm{N}, 2014)$

\section{Su historia en Cali.}

Ambas mujeres provienen de la misma zona del litoral pacífico, como característica fundamental sus relaciones previas les permiten consolidar una red de apoyo comunitaria en el nuevo sitio de vivienda: 
Hace 4 años vivo aqui en Cali. Me vine en él, como en el 2009. Eso fue en (silencio), eso fue en julio, como el 15, si el 15 de julio de 2009 (E, 2014).

4 años [se vinieron ustedes de Satinga] por lo de las Farc (...) llegamos onde, onde M (vivia) en la invasión (...) se llamaaa, se llamabaaaa (silencio) nuevo amanecer (N, 2014).

Manifiestan que las condiciones de violencia urbana en Cali, hacen que ellas establezcan relaciones limitadas o restringidas, en lo posible con personas conocidas, es decir oriundas del sitio de donde fueron desplazadas:

No acá es diferente porque como acá ya es, el pueblo y acá ya es ciudad, entonces uno está más pendiente pues porque uno no conoce bien a la gente (...) acá no pido favores! porque uno casi no les tiene confianza, o sea algunos nos hablamos y todo pero pues no es lo mismo que en Satinga, uno casi no los conoce o no hay como la misma confianza, porque igual como todos no son amigos de uno. Porque acá uno no se habla con todo el mundo, y pues acá no celebran lo mismo que uno celebraba en Satinga y pues no es la misma confianza (E, 2014)

(..) pues a uno a veces le toca dejarla sola [casa], pero pues uno no se siente tranquilo como en Satinga, porque aqui hay mucho muchacho que le gusta hacer el mal, entonces pues uno piensa que de pronto se le van a meter a la casa, pero yo por eso la dejo bien cerrada $(N, 2014)$

o sea pues tranquilo, tranquilo no [pizamos], porque eso está como calienteee, hay muchos muchachos pues malos por allá, recién que llegamos teníamos tres días y mande a mi hijo al colegio y como él no lo conocian me lo encuellaron y pa quitármele el bolso, los zapatos y el salió corriendo con mi hijo el último y después otro día también con lo mismo, entonces yo me iba salir de allá y hable con el señor de la tienda, le comenté y él llamo a los muchachos porque mi hijo me los mostró y él les dijo que como asi, que ellos tenían que era cuidar los muchachos que llegaban ahi, a la gente, que como que estaban atropellando al niño, antojes ellos dijeron que ellos no lo conocian a él, que pensaban que era de potrero, porque como en potrero está peligroso, pero que no, que lo disculparan que no volvía a pasar $(N, 2014)$

O sea a los dos vecinos que quedan, que la casa donde yo vivo queda en el medio de los dos, si yo les hablo, pero no conversamos ni nada, o sea no tenemos como una amistad que hablemos y todo sino no más los saludo y sigo y voy pasando, pero o sea no he tenido como, o sea no me ha nacido la amistad de la gente de allá (N, 2014)

(...)cuando yo llegué aqui la primera vez yo lloraba porque yo no me enseñaba a acá (...) nada me gustaba pero ya después que me fui ya adaptando y como ya uno, o sea no tenía como amigas, con quien andar entonces o sea a mi me hizo falta todo mis amigas, que yo salía a la hora que yo quería de ahí y acá todo lo que se mueve es plata mijita, (...) en la vereda vea si yo no tuve para el almuerzo hoy dia de mis hijos la vecina mi buena amiga me prestó la libra de arroz, pescado, plátano en fin, allá uno se bandea así pero acá el que no la tiene no come $(N, 2014)$ 
A ello se suman las características de la ciudad que establecen dinámicas y movilidades a las cuales las mujeres y sus familias deben adaptarse:

Si, [era un colegio ahi mismo dentro de la vereda] ahi mismo, a todos los muchachos les quedaba cerca, era fácil que se fueran a estudiar, a ella [su hija] le toca coger bus y todo, eso queda muy lejos pero pues le toca ir porque es un colegio de esos rápidos (...) que en un año hacen varios, de esos (silencio) de esos acelerados (E, 2014).

Pues yo ya me enseñe ahí y pues con mis hijos, pero si hay veces balaceras ajuera y uno le da miedo (sonrie un poco nerviosa), pero ellos no salen, se mantienen encerrados desde que salen del colegio ( $N$, 2014).

No ellos [hijos] no juegan, yo no los hago salir, me da miedo (N, 2014).

Da miedo andar solas [hijas] porque yo nunca las deje andar solas(...) es que me daba miedo porque por allá por esos barrios hay veces las matan y las vuelven y las botan, las violan y las matan entonces por eso no me gustaba que salieran ajuera del lado mío, por eso les dejaba comprado todo antes de venirme a trabajar. A ellos también les da miedo que por la pandilla, pues o una bala perdida, pero no es que ellos se hayan metido el miedo, sino que ellos el miedo es porque yo les digo (risas) (N, 2014).

Las mujeres deben asumir nuevos roles o responsabilidades, algunas representan experiencias donde lo humano queda pendiente, y la inhumanidad hace que ellas tengan actitudes más temerosas sobre las opciones y condiciones de la ciudad:

Pues uno, uno salia a barrer, pero no como esas de emsirva no, sino que uno se iba solo al centro a barrer las calles y barría y así, pero no se hacía mucho, con lo que le colaboraban a uno, $y$ de ahi pues uno vendía mangos y lo que le saliera a uno, con eso se ayudaba, porque uno no conseguía trabajo entonces habia que rebuscársela como fuera, o uno se iba pa'santa elena asi a ver que le regalaban a uno de eso que sobraba, que la gente no vendia o si se lo vendian asi muy barato a uno" (E, 2014).

No, no conseguimos [trabajo] ehh mi hermano el vendia mangos entonces él metió a Carlos ahí a vender mangos con él y yo pues fui a declarar a la UAO y allá me ayudaron, en la cruz roja primero me ayudaron con 3 meses de mercado y hasta que me llegó la ayuda como a los seis meses me llegó la ayuda (...) eso se lo dan a uno cada tres meses pero a mi hay veces se demora que los 8 meses y los 10 meses, hubo una vez que me duró cuatro meses.

Ah pues ahora estoy trabajando don Diana, pues osea en casa de familia, y yo alli me toca trabajar de lunes a sábado y le ayudo con los niños y la comida, y pues los domingos yo estoy con mi familia, arreglo mi casa, le ayudo a mis hijas, pues con el bebé y estoy pendiente de la otra que está en embarazo. ( $N$, 2014).

Pues hace dos meses está trabajando [esposo], pero porque él no estaba trabajando, cuando él trabaja tres meses para un año sin trabajar (rie) trabaja de las 7 hasta las 5 de la tarde como ayudante de construcción (N, 2014). 


\section{En Cali qué hacen y cómo se posicionan ante la violencia urbana.}

Las estrategias para solucionar problemas o conflictos son construidas según la relación previa con las personas, en tanto, provienen del mismo sitio.

No si la gente ahi me saluda y todo pero o sea yo no por lo que, por librarme como de los problemas, como que mis hijos no cojan como conflictos que porque es mi amiga ellos vayan a agarrar los hijos de ellas de amigos, o sea como para que no se haga como un grupito de muchachos, porque me da miedo, porque hay veces como están todos jovenciando entonces hacen sus grupitos, se pueden poner a jugar al lado y los otros muchachos van y les dan por, por los otros muchachos, yo no sé pero por allá de potrero pa 'allá los muchachos no pueden andar en grupo (N, 2014).

(...) se reúnen pero adentro de la casa. No, no me gusta (por fuera) porque hay veces les pueden dar al grupo porque los confunden que son de bandas Otra banda si, entonces por eso por evitar que mis hijos tengan amigos allá entonces yo también evito la amistad de la gente de allá, pero no es porque todos pueden ser malos, sino que pues yo lo hago por mis hijos, entonces por eso (N, 2014).

Ahi en ese ladito iba pasando mi marido [señala] y otro muchacho iba a la par con él y vino otro muchacho y pum le quemo tres ahí y la cabeza le calló en los pies a mi marido (risa) y le calló en los pies él a mi marido, pero eran muchachos de banda que venía otro de esos mismos y cargaba mi marido una camisa manilarga de esas de Colombia, pero en azul oscuro y el muchacho que mataron también cargaba a misma camisa, o sea que tuvo de buenas que no se lo quemaron a él, él no se movió llegó la policía y él estaba eléctrico y a él le preguntaron que si le habia, mi marido dice que él se tocaba los ojos, las orejas, porque él pensaba que le habia era sido a él y la policía lo revisó y no y nada y le dijo no usted está bien, usted los vio, no yo no vido a nadie dijo él y él los vió porque cuando venían a la par, ellos los dos están parados al frente. Si, y él los vió y los vió hasta pa donde se metieron, en la casa que se metieron y salieron con otra camisa y ahi $R$ se fue pa'onde yo estaba y ahi yo le dije hay quitate esa camisa (se rie) yo le dije y ándate con una camisa de mi sobrino y más miedo tenía yo que él, él dice que desde ahí anda como enfermo, y el muchacho calló huertecito (N, 2014).

Intentan de una manera $\mathrm{u}$ otra reconstruir segmentos de historia de vida, como anhelos de lo que tenían, pero ahora solo pueden reproducir en menor escala o momentáneamente

Vea por lo menos venga le muestro ( se para y se dirige al patio), vea alli estoy sembrando maiz y yuca, como uno en Satinga tenía palo de cosas y eso le servía pa' la comida aquí pues también y vea que están creciendo buenos (....) es que eso es para mi casa, porque como le dije uno Satinga cuando estaba bien cargado si se iba a vender, pero aquí no, osea pues para nosotros tener aqui y no tener que pedir favores de que me presten esto o una cosa y otra (E, 2014). 


\section{Discusiones.}

Prácticas culturales, Valores y Creencias de las mujeres desplazadas que viven en la ciudad de Cali.

Las características acerca de las prácticas que adoptan estas mujeres, se evidencia e identifican básicamente en dos categorias:

- prácticas formales, son aquellas que están establecidas por acuerdos tácitos por integrantes de la sociedad.

- prácticas informales, son aquellas que se dan entre miembros integrantes de la sociedad pero que nadie ha dicho que tienen que ser de dicha forma.

Por medio del relato de las dos mujeres entrevistadas, se identifica que tienen ciertas prácticas de seguridad, que como lo expresa una de ella en sus relatos, los hijos no pueden salir a la calle sin que ellas se enteren porque saben que los regañará, lo que se muestra como un mecanismo de protección ante sucesos adversos, lo cual ellos adoptan como una práctica que en algún momento se ha impuesto, la cual se identifica como de prácticas informales.

De la misma forma se logra identificar que ellas han interiorizado que desde su rol de mujeres deben estar al pendiente de los que haceres del hogar, sin importar que sean además trabajen todo el día, esto es adoptado como una práctica entre los miembros de la sociedad, que no necesariamente se ha dicho pero que se sabe de forma indirecta que es como funciona su sistema de convivencia.

Con respecto a los valores, rescatamos como importante el papel de la solidaridad entre los miembros de la comunidad, y sobre todo entre los grupos de mujeres que se ayudaban en sus lugares de origen cuando a alguna le hacía falta algo, inmediatamente se compartían, sin esperar nada a cambio, muestra de una relación cooperativaen la relación de género.

Finalmente respecto a las creencias, se nombra algo acerca de un leyenda en la cual ellas creen y la llaman "la tunda", dentro del relato de una de las mujeres, ella expresaba que le daba miedo a veces dejar la puerta abierta, porque en Satinga se creía que tal "visión se llevaba a los niños", generando preocupación sobre dejar las puerta de su casa abierta. De lo cual se deduce que "la leyenda" puede ser una representación de los integrantes de los grupos armados, puesto que tienen los mismos movimientos, es decir se mueven en el monte, a veces no se ven y van en búsqueda de llevarse a los niños.

Cómo las mujeres víctimas del conflicto armado en Colombia, provenientes de la costa pacífica, resuelven sus problemas de violencia urbana en Cali.

Teniendo en cuenta el "Informe comisión la verdad de las mujeres víctimas del conflicto en Colombia" en relación con los discursos presentes en los relatos de las dos participantes, se logra identificar que las mujeres al llegar a la zona rural o a un nuevo territorio, después de ser desplazadas se aíslan de las personas a su alrededor, limitando el establecimiento de nuevas relaciones. 
En el relato de las entrevistadas se nombraba la desconfianza que sentian hacia los nuevos vecinos, pues las experiencias vividas de temor y violencia generan incertidumbre que les impide continuar con la cotidianidad de sus vidas, esperando que algo "malo" pueda sucederles (no identificar "quiénes son los buenos y quienes son los malos", por miedo a una bala perdida); tal como se menciona en "La extensión de la amenaza: incertidumbre y sin sentido" y "Estar como alejado de todo: aislamiento social" ( "Informe comisión la verdad de las mujeres víctimas del conflicto en Colombia”, 2013) . De hecho, el miedo y la desconfianza afecta su vida emocional, las relaciones con los demás y el contexto.

De igual forma, en los capítulos “Tengo que cuidarme. Precaución, autocuidado y seguridad", "desconfiar... de todo y de todos" y "esconderse, encerrarse, hacerse invisible", permiten evidenciar en el discurso, que lo vivido en sus lugares de origen debido al conflicto armado, lo re-viven en la ciudad como violencia urbana, y por lo cual recurren a estrategias como invisibilizarse para desaparecer y protegerse a sí mismas y a sus familias.

Mientras que la subcategoría del informe denominada "El territorio como fuente de peligro" es relevante para la investigación, pues el territorio es entendido por las mujeres como el espacio de ocurrencia hechos violentos que es fuente de peligro y genera miedo. En los relatos se identifica que ello no solo sucede en los lugares de donde provenían, sino también con los nuevos sitios de residencia, ya que estas mujeres viven con el miedo y la angustia vivida en sus lugares de origen.

También se identifica una relación entre "Amenazas y hostigamiento familiar" y el relato de las dos mujeres, puesto que en ambos expresan aquellos hostigamientos o sucesos vividos en sus lugares de origen, por parte de los grupos armados (guerrilla, paramilitares y otros). En los relatos se lograba extraer la manera como este tipo de sucesos afectaban no solo a la mujeres sino a sus familias, lo que en consecuencia las atemorizaba o invadia de miedo porque sentían que estaban en peligro cada uno de los miembros de su familia.

Es importante ver como en cada uno de los relatos las mujeres expresan que ellas se desplazan de sus lugares de origen hacia otras ciudades para proteger a sus familias de cualquier suceso violento, que ante las amenazas por parte de esos grupos armados, ellas usan diferentes estrategias, en este caso salir de sus viviendas como respuesta a los actos de violencia de esas personas.

Por último, lo económico y el cambio de roles, es otro punto de afectación de las mujeres pues ante la presencia de dificultades económicas se sobrecargan de roles, se afectan las Relaciones, proyectos, roles y subsistencia y se presentan rupturas en lo laboral que determinan dificultades para empezar de nuevo. Las 2 mujeres deben recurrir a diferentes tipos de trabajo, muchos de los cuales afectan sus creencias y valores; asimismo se identifica un cambio de rol en tanto que al desplazarse pierden sus ingresos y deben aportar dinero a la casa (empleo doméstico, barriendo en la calles, recogiendo los alimentos que se han desechado en las galerías). Lo que podría traducirse o verse como una forma de violencia urbana, debido a que por su condición de desplazamiento las oportunidades de acceder a otro tipo de trabajos disminuye. 


\section{Conclusiones.}

Esta investigación como ejercicio metodológico desde la metodología feminista, aporta a la psicología comunitaria, ya que logra desnaturalizar por medio de este ejercicio diferentes relaciones de poder que se identifican en contextos urbanos.

De igual forma, se muestra en el discurso de las participantes, indicios de cómo en un contexto urbano, el establecer relaciones de poder influye en los mecanismos de protección que estas mujeres crean para cuidar a sus familias y relacionarse con las personas que las rodean. De esto se puede inferir que tal como lo señala la psicología comunitaria es posible encontrar que las relaciones legítimas o autoridades se establecen o varían de acuerdo al contexto en el que se encuentran.

La metodología de investigación feminista facilita el proceso de investigación, puesto que en psicología comunitaria estamos dando por sentado la presencia de diferentes realidades y por medio de la investigación logra identificarse que se viven realidades iguales en dos contextos aparentemente diferentes.

Es posible desde el ejercicio investigativo mostrar o poner en evidencia aquello que es obvio, aquello que todo el mundo dice saber o conocer, pero en el momento de darlo nombre, forma, caracterizar ese algo no sé hace

Desde esta investigación, es posible establecer futuras investigaciones de corte exploratorio y descriptivo bajo la perspectiva de diferentes actores asociadas al bienestar y desarrollo social de las mujeres, sobre: La forma cómo las mujeres siguen siendo víctimas en un contexto urbano después de haber sido víctimas de un conflicto sociopolítico; Las habilidades sociales de estas mujeres en los contextos urbanos; las formas de violencia que se ejercen en un contexto urbano; y el impacto del espacio (físico para necesidades como la recreación, educación y vivienda) que se les proporciona a las mujeres a familias desplazadas en un contexto urbano.

\section{Referencias Bibliográficas.}

Herrero , A. (Septiembre de 2010). Los conflictos armados en el pensamiento económico . Obtenido de www.iecah.org: http://www.iecah.org/web/images/stories/publicaciones/ documentos/descargas/documento7.pdf

Barney , A. G., \& Guizado, A. C. (1990). La Violencia Urbana En Colombia: Sintesis de un estudio exploratorio en una ciudad Colombiana. Boletín Socicoeconómico, 42( $\left.\mathrm{N}^{\circ} 20\right)$.

Bello, M. N. (2001). Biblioteca Digital en Violencia Sociopolitica, Acción sin daño y Construcción de Paz. Obtenido de www.bivipas.info: http://www.bivipas.info/ bitstream/10720/300/1/L-121-Bello_Martha-2001-147.pdf

Campbell, R., \& Wasco, S. (2000). Feminist Approaches to Social Science: Epistemological and Methodological Tenets. In American Journal of Community Psychology, 773-791. 
Catamuzkay Cárdenas, K., \& Franco Díaz, N. A. (2005). Diagnóstico situacional de la población en sitación de desplazamiento-PSD- asentada en el municipio de Cali. Cali.

Céspedes, L. M. (2010). La violencia sexual en contra de las mujeres como estrategia de despojo de tierras en el conflicto armado colombiano. Revista Estudios Socio-Jurídicos, 273-304.

Comisión de la verdad y reconcilliación. (28 de Agosto de 2003). Capitulo 1. Secuelas psicosociales. Obtenido de www.cverdad.org.pe: http://www.cverdad.org.pe/ifinal/pdf/ TOMO\%20VIII/TERCERA\%20PARTE/I-PSICOSOCIALES.pdf

Contreras, M. H. (2003). El conflicto armado en colombia. Revista de Derecho, 122.

El país. (13 de Junio de 2013). Durante el 2012 fueron desplazadas 256.590 personas en Colombia. Obtenido de www.elpais.com.co: http://www.elpais.com.co/elpais/ internacional/noticias /durante-2012-fueron-desplazados-256590-personas-colombia

El país. (7 de Marzo de 2014). Valle, la región con más homicidios de mujeres en el país el año pasado: Defensoría. Obtenido de www.elpais.com.co: http://www.elpais.com.co/ elpais/judicial/noticias/segun-defensoria-valle-region-con-homicidios-mujeres

González, N. M. (2009). Las nuevas tribus urbanas de Calí. Desplazamiento forzado desterritorialización y reterritorialización. HiSTOReLo. Revista de historia regional y local, 32-85. Obtenido de http://dialnet.unirioja.es/servlet/articulo?codigo=3650490

Hernández, L. (2009). Población desplazada busca nuevas formas de desplazarse. Cali: Agencia Universitaria de periodismo Científico AUPEC. Obtenido de http://aupec. univalle.edu.co/informes/2009/abril/desplazados.html.

Langa, A. (2010). Los conflictos armados en el pensamiento económico. Instituto de Estudios sobre Conflictos y Acción Humanitaria, 46. Obtenido de http://www.iecah.org/web/ images/stories/publicaciones/documentos/descargas/documento7.pdf.

Leal Buitrago, F. (18 de Marzo de 2012). Por qué la guerra en Colombia. Obtenido de www. razonpublica.com: http://www.razonpublica.com/index.php/conflicto-drogas-y-paztemas-30/2808-por-que-la-guerra-en-colombia.html.

López , Z., Ochoa , S., Alcaraz , G., Leyva, R., \& Ruíz, M. (2010). Vulnerabilidad a infecciones de transmisión sexual y SIDA en mujeres en situación de desplazamiento forzado. Medellin, Colombia. Investigación y educación en enfermería, 11-22.

Mogollón , A. S., \& Pérez, M. L. (2006). Opinión de las mujeres desplazadas sobre la repercusión en su salud del desplazamiento forzado. Gaceta sanitaria: Organo oficial de la Sociedad Española de Salud Pública y Administración Sanitaria, 260-265.

Mogollón , A., \& Pérez, M. (2006). Opinión de las mujeres desplazadas sobre la repercusión en su salud del desplazamiento forzado. Gaceta sanitaria: Organo oficial de la Sociedad Española de Salud Pública y Administración Sanitaria, 260-265. 
Organización femenina popular. (2014). Observatorio de las violencias y la discriminación contra las mujeres en el Magdalena Medio. Barrancabermeja: Organización femenina popular.

Organización Panamericana de la Salud para la Organización Mundial de la Salud. (2002). Informe Mundial sobre la violencia y la salud. Washington: Organización Panamericana de la Salud para la Organización Mundial de la Salud.

Restrepo, A. M. (2005). Palabras y resistencias de mujeres del Putumayo en contexto del conflicto armado colombiano. Convergencia: Revista de ciencias sociales, 85-114.

Ruiz Romero, G. (2011). Mujeres del nunca más: la voz de la ausencia. Prisma Social: revista de ciencias sociales, 1-29.

Ruta pacífica de las mujeres. (2013). La verdad de las mujeres víctimas del conflicto armado en Colombia. Bogotá: Ruta pacífica de las mujeres.

Saavedra, L. H. (Abril de 2009). Población desplazada busca nuevas formas de organizarse. Obtenido de www.aupec.univalle.edu.co: http://aupec.univalle.edu.co/informes/2009/ abril/desplazados.html

Sánchez Torres , F., \& Díaz, A. M. (2005). Los efectos del conflicto armado en el desarrollo social colombiano, 1990-2002. Bogotá: Uniandes. Obtenido de https://economia. uniandes.edu.co/component/booklibrary/478/view/46/Documentos\%20CEDE/444/ los-efectos-del-conflicto-armado-en-el-desarrollo-social-colombiano-1990-2002

Yepes, O. C. (2007). ¿El silencio de las inocentes?: violencia sexual a mujeres en el contexto del conflicto armado. Opinión Jurídica, 89-101.

\section{Nota:}

${ }^{3}$ Artículo producto de la Investigación: "Violencia urbana y estrategias de protección de mujeres en Cali", en la modalidad Investigación empírica no institucional. Programa de Psicología, Facultad de Psicología, Universidad de San Buenaventura, Cali. Junio 11 de 2014. 